\title{
International banking centres: a network perspective $^{1}$
}

International banking centres have attracted renewed interest recently, as established centres compete over more dimensions while new centres emerge. Comparative studies often focus on indicators of financial activity in a particular location, but the prominence of an international banking centre also reflects cross-border linkages with banks in other locations. This feature combines these cross-border linkages into a global network and identifies important banking centres using network methods. The range of measures discussed capture the degree to which banking centres can be considered central to the international banking network.

JEL Classification: F34, G21, L14, C45.

The rise of international financial centres is a topic of long-standing interest. Their historical formation has been studied from various angles (Kindleberger (1974), Cassis (2006)). The topic is receiving renewed attention as the preeminent global financial centres, London and New York, are increasingly complemented by regional centres such as Hong Kong SAR and Singapore, and as new financial centres in the Arab world seek to establish an international presence. The activities of banks within international financial centres often receive special scrutiny under the heading of international banking centres (eg Choi et al (1996, 2003)).

But what exactly is an international banking centre? Banking centres are often defined as an agglomeration of banking activity in a specific location, performing a range of functions or combining a number of markets. But the term "centre" also conveys a notion of space, that of a position in relation to other locations. From that perspective, a banking centre can be viewed as the centre of a network formed by banking linkages between locations.

Drawing on the BIS international banking statistics, this feature applies methods from the literature on networks to identify banking centres that are particularly well placed or play an important role in international banking. The results, it should be stressed, are not intended as overall rankings of banking centres, for while the network perspective captures international balance sheet

1 The views expressed in this article are those of the author and do not necessarily reflect those of the BIS. The author is grateful to Claudio Borio, Patrick McGuire, Frank Packer, Nikola Tarashev, Kostas Tsatsaronis, Christian Upper and Philip Wooldridge for helpful comments. 
linkages, the local aspects emphasised in more traditional assessments are also undeniably important. Rather, the feature intends to show how a new and complementary approach might be used in assessing the vitality of international banking centres.

\section{From size to network structure}

It is well known that a small number of countries account for a large global share of international banking activity. ${ }^{2}$ Graph 1 shows the evolution of market shares in cross-border activity of the largest banking centres. In the second quarter of 2007, banks located in the United Kingdom held $20.4 \%$ of international bank assets on their books, and $22.8 \%$ of international bank liabilities, largely as a result of international deposit placements. The next largest banking centre is the United States, whose share in liabilities (12.6\%) exceeds that in international assets $(9.2 \%)$, reflecting considerable onlending to the domestic economy. The market share of banks in Japan rose substantially during the 1980s, but reversed thereafter as banks weakened by financial distress withdrew from the international market. The divergences over time in the lower ranks suggest that these positions are more contestable, with banks in Germany, France, the Cayman Islands and Switzerland oscillating in the range of $3-10 \%$ of market share.

Market share identifies centres with substantial international banking activity. But what accounts for their size? In what sense are these locations central, and what role do they perform in the international banking system?
A small number of countries account for a large share of international banking activity

Banks in international centres generate linkages across space ...

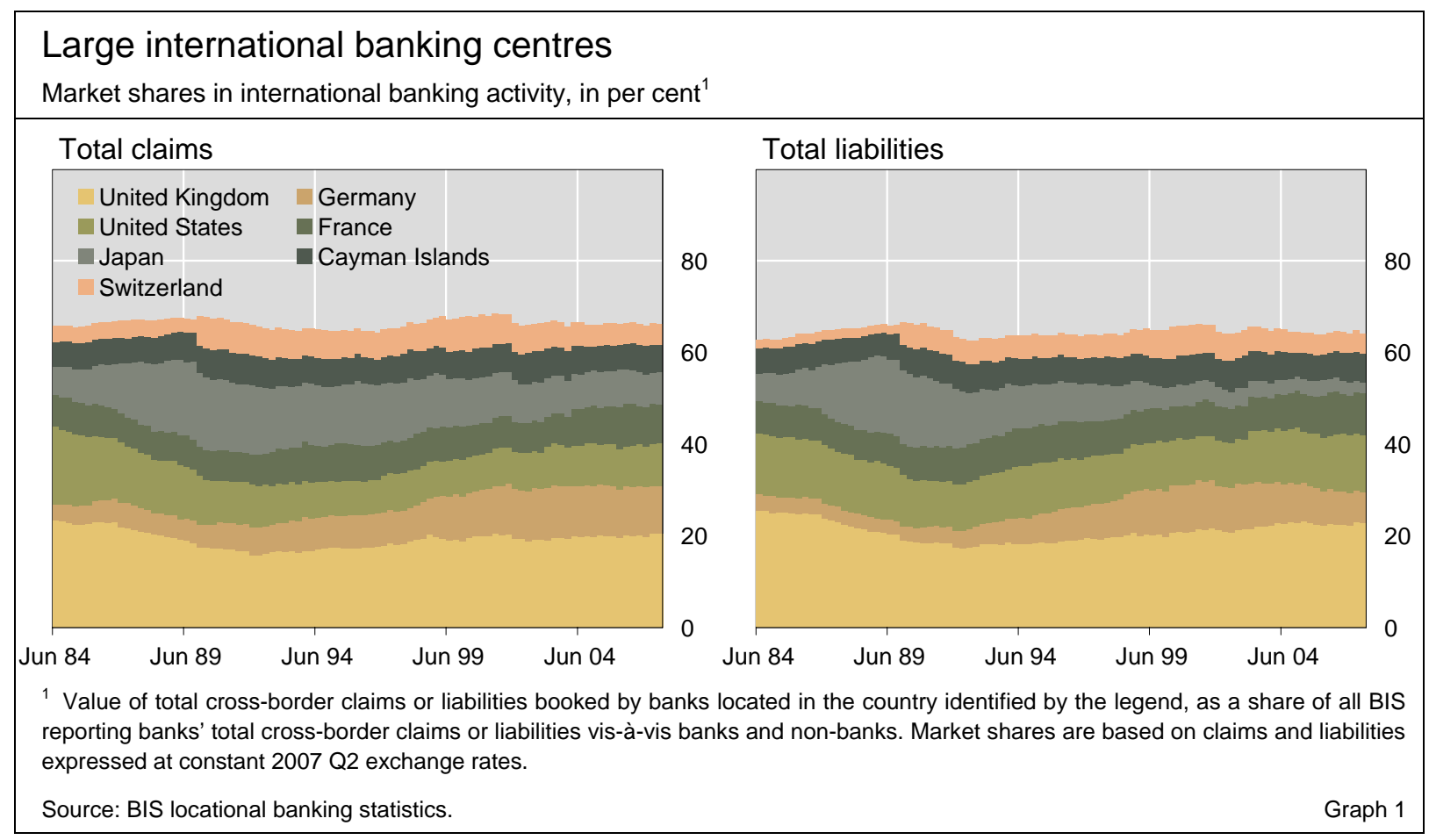

2 International banking comprises cross-border activity in all currencies, and operations with domestic residents in foreign currencies. Market share in international banking activity is a standard measure of the size of an international banking centre, and one of many indicators of international financial activity more generally. 
A useful starting point is to observe that market share in international banking activity is evidence that other countries are participating in a financial centre. Banks from foreign countries set up offices in a financial centre to engage in a broad range of financial activities, including information gathering, international borrowing and lending, trading in financial markets, and clearing and settlement of payments and securities (Kindleberger (1974), Gehrig (2000)). In so doing, banks located in the financial centre generate linkages across space, with their headquarters, with foreign offices abroad, or with institutions elsewhere for which they act as correspondent banks.

The linkages that such an agglomeration of financial activity entails can be regarded as a network. ${ }^{3}$ A network consists of a set of nodes connected by links. In the present context, each node represents a banking centre, ie the set of banks located in a particular country or jurisdiction. A link to another centre represents financial claims on entities located there. A network perspective on international banking activity relies on bilateral data. The most comprehensive international banking data with global coverage are the BIS locational statistics. They capture the geography of banking activity in a consistent fashion. ${ }^{4}$ Every quarter, banks in 40 reporting countries report their gross stocks of international assets and liabilities, with breakdowns by currency, instrument, and sector (banks versus non-banks). Most importantly for the analysis, positions are reported vis-à-vis 212 countries or jurisdictions. The ability to identify bilateral positions for individual country pairs is a distinct advantage over other international financial data lacking counterparty information.

The network described here includes linkages between banking centres as well as their linkages with non-banks in every location. It is constructed as follows. To keep the focus on banking centres, banks and non-banks within the same country are treated as two separate nodes within the network. (This extends the size of the network to 424 nodes.) The interbank segment, relating banks of different locations to each other, accounts for some $60 \%$ of international banking activity, much more than the interbank share in domestic markets. ${ }^{5}$ The non-bank segment comprises claims and liabilities booked by banks vis-à-vis every non-bank location. The fact that banks in all reporting

3 Viewing the international banking market as a network also corresponds to the nature of the market. Deals are not made against a central counterparty in a Walrasian market, but through a decentralised web of institutions where bilateral contact plays a central role (eg Stigum (1990)).

4 The locational banking statistics treat all entities on a residence basis. By contrast, the BIS consolidated banking statistics, while also reporting banks' foreign claims on a residence basis, consolidate reporting banks by their nationality. This mix of residence and nationality principles is appropriate for assessing risk exposure, but less so for network analysis. Hattori and Suda (2007) apply some network measures to the consolidated banking statistics.

5 Reporting countries generally provide data on banks and other credit institutions with international business, including major investment banks. The interbank data include interoffice claims, ie cross-border positions between offices of the same banking organisation. This geographical relocation of banking activity should not be disregarded. 
countries disclose both assets and liabilities can be exploited to alleviate the problem of an incomplete reporting population. ${ }^{6}$

The pattern and size of linkages in such a network clearly contain a wealth of information. Such information can be used to characterise features of the network as a whole, as in much of the physics literature on networks (Newman et al (2006)). The information can also be used to characterise individual nodes, as in social network analysis concerned with the importance of actors in a group (Wasserman and Faust (1994)). To identify which locations act as international banking centres, this feature builds on the second approach. The idea is to infer, from the pattern of linkages, in what sense a banking centre is central in the international banking network. The results apply to banking centres, and do not extend to financial centres more broadly, partly because links between non-banks are not available in the data.

The analysis takes account of the fact that the international banking network differs from those studied elsewhere in the literature: the network is directed, dense and valued. The network is directed, because a link from Japan to Singapore is not the same as a link in the other direction: the direction indicates which location is holding the claims (ie liabilities of the other location). The network is dense, because $39 \%$ of potential links are active, much more than studies find for domestic interbank networks. Moreover, the network is valued, because links are not merely present or absent, but consist of monetary values that vary enormously across space (Gini coefficient 0.94 ). As a result, at least as important as understanding where links are is how large the associated exposures are. Since the network literature remains largely silent on valued networks, it is important to employ and extend methods suitable for this case.

\section{Identifying international banking centres by network methods}

This section characterises the importance of banking locations according to various network measures that are associated with being an international banking centre (or "global hub"). Degree, closeness and betweenness relate to how a centre is connected and positioned in relation to other countries; intermediation also takes the size of exposures into account; and prestige brings the identity of counterparties into the picture. The measures, derived in the Box, are computed on the entire network (including non-bank locations), but only banking centres are ranked in Table 1.

6 The procedure overlays reported claims and liabilities, which achieves the following. Banks in Finland, for example, report claims on all other countries including Russia. As a non-reporting country, Russia does not report what entities located there lend to banks in Finland, but this can be inferred from the deposits that banks in Finland report to have obtained from entities in Russia. Positions are observable whenever a reporting bank is on either side of the transaction, ie as creditor or as debtor. (Only positions between non-reporting banks and between non-banks remain unobservable.)

Important banking centres can be identified using network methods 


\begin{tabular}{|c|c|c|c|c|c|c|c|}
\hline \multicolumn{8}{|c|}{ International banking centres } \\
\hline & \multirow{2}{*}{$\begin{array}{l}\text { Market } \\
\text { share }^{1}\end{array}$} & \multicolumn{6}{|c|}{ Measures of network centrality ${ }^{2}$} \\
\hline & & In-degree & Closeness & Betweenness & \begin{tabular}{|l|} 
Intermediation \\
\end{tabular} & \multicolumn{2}{|l|}{ Prestige } \\
\hline United Kingdom & $22.1 \quad(1)$ & 89.7 (1) & 0.82 (1) & 12.8 (1) & 20.5 (1) & 8.59 & \\
\hline United States $^{3}$ & $12.9 \quad(2)$ & $43.9(20)$ & $0.60(24)$ & $1.4(25)$ & $4.3(5)$ & 4.46 & \\
\hline France & $6.6 \quad(3)$ & 80.5 (4) & 0.80 (2) & 9.9 (2) & $15.7 \quad(2)$ & 3.79 & \\
\hline Cayman Islands & 6.1 (4) & $61.5(11)$ & $0.63(15)$ & $2.7(12)$ & $1.4(16)$ & 1.87 & \\
\hline Germany & $5.6 \quad(5)$ & $81.2 \quad(3)$ & 0.77 (3) & 8.2 (3) & 9.5 (4) & 2.60 & \\
\hline Switzerland & 4.5 (6) & $84.5 \quad(2)$ & 0.75 (4) & $8.2(4)$ & $11.0 \quad(3)$ & 3.56 & \\
\hline Ireland & $3.6 \quad(7)$ & $50.0(16)$ & $0.63(16)$ & $1.6(21)$ & $0.8(25)$ & $1.04(1$ & \\
\hline Netherlands & 3.5 (8) & 65.5 (7) & 0.69 (7) & $3.6 \quad(6)$ & 2.8 (8) & 1.38 & (8) \\
\hline Belgium & $2.9 \quad(9)$ & 79.1 (5) & 0.70 (5) & $5.5 \quad(5)$ & $3.3(7)$ & 1.75 & \\
\hline Italy & $2.8(10)$ & $63.6 \quad(8)$ & $0.65(13)$ & $2.6(14)$ & $1.3(19)$ & $1.02(1$ & \\
\hline Spain & $2.6(11)$ & $62.0(10)$ & $0.67(12)$ & $3.0(10)$ & $2.1(12)$ & $1.07(1$ & \\
\hline Japan & $2.6(12)$ & $48.8(18)$ & 0.65 (14) & $2.1(15)$ & $0.9(24)$ & $0.81(1$ & \\
\hline Luxembourg & $2.5(13)$ & 67.1 (6) & 0.67 (11) & 3.1 (9) & $1.9(13)$ & 1.19 & (9) \\
\hline Singapore & $2.0(14)$ & $40.9(23)$ & $0.63(18)$ & $1.7(19)$ & $2.4(10)$ & $0.97(1$ & \\
\hline Australia & $1.7(15)$ & $53.5(14)$ & $0.63(17)$ & 3.3 (7) & $2.7(9)$ & $1.02(1$ & \\
\hline Rank correlation ${ }^{4}$ & 1.00 & 0.85 & 0.71 & 0.68 & 0.66 & & .95 \\
\hline \multicolumn{2}{|c|}{ Largest relative change $^{5}$} & \multicolumn{6}{|c|}{ Positive } \\
\hline & & $\mathrm{CH}+4$ & $\mathrm{KO}+21$ & $C A+11$ & AT +14 & $\mathrm{PA}+$ & +23 \\
\hline & & LU +7 & TW +17 & $\mathrm{TW}+14$ & AW +99 & JE & \\
\hline & & $C A+10$ & $\mathrm{DK}+13$ & $A U$ & IN +16 & $\mathrm{CH}$ & +2 \\
\hline & & IN +16 & AT +11 & SV +53 & $\mathrm{PA}+27$ & LU & +4 \\
\hline & & $\mathrm{BE}+4$ & $\mathrm{PK}+44$ & $\mathrm{KE} \quad+60$ & $\mathrm{CH}$ & $\mathrm{MO}+$ & +11 \\
\hline & & \multicolumn{6}{|c|}{ Negative } \\
\hline & & $\mathrm{CR}-31$ & MT $\quad-28$ & VN -130 & CR $\quad-79$ & HR & -8 \\
\hline & & SG $\quad-9$ & KZ -42 & SK -118 & VN -129 & IS & -8 \\
\hline & & $\mathrm{IE} \quad-9$ & -9 & IE $\quad-14$ & SK -117 & NO & -5 \\
\hline & & $\begin{array}{ll}\mathrm{KY} & -7\end{array}$ & $\mathrm{KY}-11$ & $\begin{array}{ll}\mathrm{KY} & -8\end{array}$ & IE $\quad-18$ & $J P$ & -5 \\
\hline & & US -18 & US -22 & US -23 & KY $\quad-12$ & IE & -5 \\
\hline \multicolumn{8}{|c|}{$\begin{array}{l}\text { Aruba (AW), Australia (AU), Austria (AT), Belgium (BE), Canada (CA), the Cayman Islands (KY), Croatia (CR), Denmark (DK), } \\
\text { El Salvador (SV), Hungary (HR), Iceland (IS), India (IN), Ireland (IE), Japan (JP), Jersey (JE), Kazakhstan (KZ), Kenya (KE), } \\
\text { Korea (KR), Luxembourg (LU), Macao (MO), Malta (MT), Norway (NO), Pakistan (PK), Panama (PA), Singapore (SG), Slovakia (SK), } \\
\text { switzerland (CH), Taiwan, China (TW), the United Kingdom excluding islands (UK), the United States including international banking } \\
\text { facilities (US) and Vietnam (VN). }\end{array}$} \\
\hline \multicolumn{8}{|c|}{$\begin{array}{l}{ }^{1} \text { Market shares are calculated on total international bank liabilities excluding liabilities to bank residents. For non-reporting countries, } \\
\text { bank liabilities are inferred from the interbank claims of BIS reporting banks (their liabilities to non-banks remain unobserved). } \\
2 \text { In-degree, betweenness and intermediation are expressed in per cent, closeness as an inverse distance, and prestige is normalised } \\
\text { to sum to } 100 \text {. Refer to the Box for details. }{ }^{3} \text { Calculating the measures on a network restricted to those countries on which the } \\
\text { United States fully reports raises the US rank on in-degree (to } 19 \text { ) and closeness (to } 22 \text { ). }{ }^{4} \text { Kendall rank correlation with the ranking } \\
\text { of } 212 \text { banking centres on market share. }{ }^{5} \text { Centres with the largest relative change in their rank, compared to their rank on market } \\
\text { share. }\end{array}$} \\
\hline Source: BIS. & & & & & & Tabl & le 1 \\
\hline
\end{tabular}

\section{Degree}

Connectedness is measured by the number of links to and from a node
To qualify as a global hub, a banking centre should be well connected in the international banking network. Being connected to many counterparties enables a banking centre to interact readily with other locations around the 
globe. This enables hubs to perform a variety of functions, including the global distribution of liquidity (Niehans and Hewson (1976), Johnston (1983)). Connectedness can be quantified by the measure called degree, ie the total number of links that emanate from, or point to, a node.

Banking centres generally establish a presence on both sides of the market. If they borrow from many locations (in-degree), they also tend to lend to many locations (out-degree; Graph 2, left-hand panel). Interestingly, the most connected hubs, by this measure, take deposit placements from a greater number of locations than they lend to: for instance, banks in the United Kingdom take deposits from 382 locations in the world (90\% of all bank and non-bank locations), while lending to $79 \%$ of locations. The mid-field settles near $50 \%$ on both in- and out-degree, except for Taiwan (China), Korea and Denmark, where banks lend to nearly twice as many locations as they borrow from.

In-degree may be more noteworthy because it reflects the choices of entities abroad to place funds with a centre, whereas out-degree results to a larger extent from a centre's own decisions. The in-degree ranks following the United Kingdom are occupied by Switzerland, Germany, France and Belgium, each chosen as counterparties by over $70 \%$ of locations. Some locations are not as well connected as their global market share would suggest. The United States and the Cayman Islands, ranked second and fourth on market share, rank 20th and 11th on in-degree, respectively. ${ }^{7}$ By contrast, the banking centres of Canada, Macao and India are highly connected for their size, and post corresponding gains relative to their rank based on market share.

Relations with non-banks contribute materially to the in-degree of several banking centres (Graph 2, right-hand panel). Indeed, the most connected hubs, together with Jersey and Luxembourg, have liabilities to non-banks virtually everywhere in the world. Banks in Jersey and India receive funds disproportionately from non-bank counterparties - they engage in sectoral transformation from non-bank liabilities to interbank claims. By contrast, banking centres below the $45^{\circ}$ line derive their degree to a greater extent from the interbank market. This group includes several important emerging markets, such as Brazil, Chile, Mexico and Turkey.

\section{Closeness}

A second network criterion is that a banking centre aspiring to a global position should be close to the rest of the world. A suitable measure of closeness, which allows for direct and indirect linkages, is the inverse of the average "distance" from a banking centre to all other locations, where distance refers to the number of links on the shortest path (see Box). Thus one half would be the score of a banking centre that, on average, reaches other locations in two

This is partly explained by the caveat that the United States does not report the full country breakdown for all regions. Excluding known unreported countries raises US in-degree to $46 \%$ (rank 19). A different way of addressing the issue is to merge the Cayman Islands (reporting a full breakdown) with the United States in a single node; their combined in-degree equals $65 \%$ (rank 8).

Relations with nonbanks contribute to connectedness 


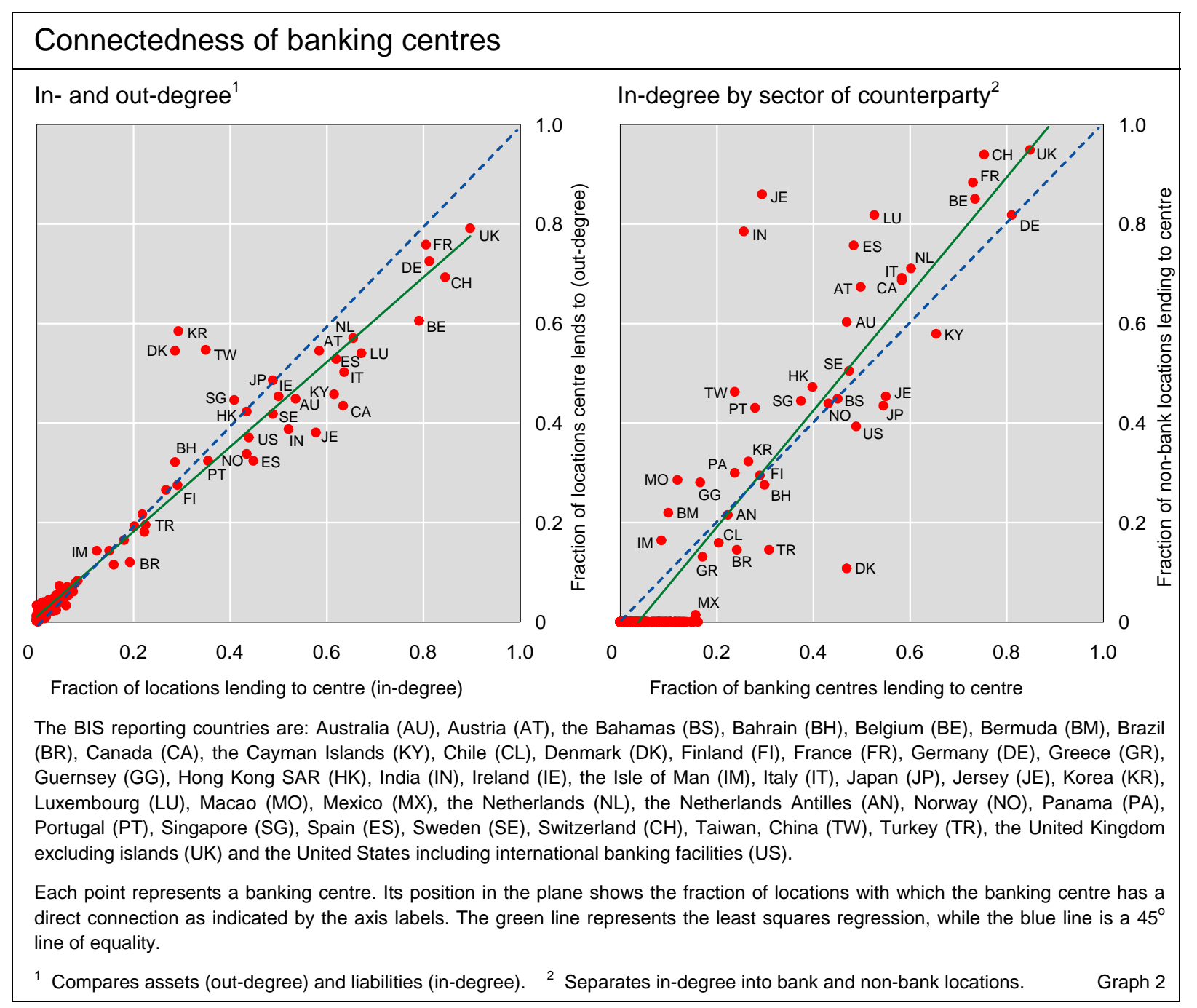

Closeness identifies centres with the broadest reach to smaller countries

steps. The maximum score of 1 would be attained by a global hub directly connected to all locations.

While large banking centres tend to be strongly connected to each other as well as to the major economies, the closeness measure helps identify those centres with the broadest reach to smaller and more remote countries. The United Kingdom leads the closeness ranking, with a score of 0.82 (implying an average distance to other locations of 1.22; Table 1). However, the topology of international banking does not resemble a pure star network in which a single centre connects all other nodes, since several other banking centres are also well placed to reach remote areas (Graph 3). Four European centres attain scores over 0.7, and five Asian centres one of over 0.6. Indeed, Korea and Taiwan (China) post the largest gains in their ranking, relative to that based on market share, as a result of diversifying their lending across many locations.

The closeness of an international banking centre may be particularly important from the perspective of small and remote countries. Suppose a bank from a small Asian country sets up an office in Hong Kong SAR, for example, in order to access a global pool of liquidity or to finance trade with third parties. The resulting linkage effectively moves the country closer to Hong Kong, in a network sense. This not only raises (marginally) Hong Kong's closeness score, but also raises (perhaps substantially) the small country's score because it is 


\begin{tabular}{|l|r|r|r|r|r|}
\hline \multicolumn{7}{|l|}{ Representation of foreign banks in international banking centres } \\
\hline & CH & FR & HK & SG & UK \\
\hline Number of BIS reporting banks ${ }^{2}$ & 108 & 268 & 194 & 153 & 337 \\
Headquartered in the reporting country & 41 & 120 & 19 & 5 & 73 \\
Headquartered in another reporting country & 53 & 127 & 131 & 126 & 198 \\
Headquartered outside the reporting area & 14 & 21 & 44 & 21 & 61 \\
\hline${ }^{1}$ Shown here: Switzerland (CH), France (FR), Hong Kong SAR (HK), Singapore (SG) and the United Kingdom (UK). & 2 Only the \\
main office of a bank is recorded, regardless of the number of offices the bank maintains in the country. The number of banks \\
headquartered outside the reporting area of 40 BIS reporting countries is indicative of the representation of banks from emerging \\
markets. (The columns add to less than the total number of reporting banks in some cases because of unallocated banks.) \\
Source: BIS locational banking statistics. \\
Table 2 \\
\hline
\end{tabular}

now only two steps away from all of Hong Kong's counterparties. The presence of foreign banks is indeed one of the most cited features of financial centres (Reed (1981), Choi et al (1986, 1996, 2003)). The BIS locational statistics also show that major centres host many foreign banks (Table 2). The broad representation of banks from emerging markets in the United Kingdom helps to explain its remarkable global reach.

\section{Betweenness}

Locations that are not directly linked can reach each other through banks in a third country. The important role such middlemen play in a network is captured by the following criterion: to qualify as a global hub, a banking centre should be in a position to connect other locations with each other. This can be quantified by betweenness, the frequency with which a banking centre lies on the shortest path between two unconnected locations (see Box). A high score on this criterion can be thought of as measuring a centre's ability to bring together customers from both sides of the market (lenders and borrowers).

Among the largest banking centres, the ranking differs little from that based on market share. Banks in the United Kingdom have a 13\% chance of being on the shortest path between any two unconnected locations (non-bank locations included). Banks in Germany, France and Switzerland follow closely, but perhaps for a different reason. The United Kingdom's score reflects London's position as a host to many foreign banks, whereas Germany, France and Switzerland are home to multinational banks generating considerable interoffice activity across borders. The ranking differs more in the mid-field, indicating that betweenness captures an aspect of banking centres quite distinct from their size (the rank correlation with market share is 0.65 ; Table 1). The gains in ranking witnessed by Canada, Taiwan (China) and Australia suggest that their banking centres are positioned strategically with respect to some region or part of the network.

\section{Intermediation}

To qualify as a global hub, a banking centre should also perform an important intermediary role in the international banking network. There can be many

The intermediation measure captures the intensity of links by incorporating portfolio shares 
Intermediation does not always go with size
Prestige reflects the importance of counterparties intermediaries between any pair of unconnected locations. ${ }^{8}$ Since the betweenness measure treats each path (hence each intermediary) as equivalent, regardless of value, it may underestimate the importance of hubs as focal points. The intermediation measure proposed here captures the intensity of links by incorporating the portfolio shares of each banking centre's international claims. The measure calculates the share of each sender's portfolio that a banking centre transports to every recipient, and averages this product of shares across all country pairs (see Box).

The largest hubs also appear as the most important intermediaries (Table 1). The likelihood that a dollar transferred between any country pair goes through the United Kingdom is highest (20\%), followed by France, Switzerland, Germany and the United States. For the large banking centres, the intermediation measure tends to exceed betweenness, which indicates that large hubs are the preferred conduits when there are several paths. This is not because they would send a large share of their portfolio to each recipient, but because they receive such a high portfolio share from many locations. This also explains why intermediation correlates with size: taking deposits enlarges a hub's reported size.

However, not all banking centres perform an intermediation function commensurate with their size. Some large offshore centres score quite low on global intermediation, because they concentrate their positions on a few locations, eg the Cayman Islands on US entities. Conversely, some mid-sized centres attain a high score through a combination of connectedness and specialisation. Specifically, decomposing the intermediation measure by sector shows banks in Switzerland to be the main intermediary between non-bank pairs, while banks in the United Kingdom lead the ranking for pairs with banks on either side. Similarly, calculating intermediation separately for pairs across and pairs within the same continent demonstrates the importance of global and regional hubs. While the largest banking centres are truly global hubs intermediating across all continents, a significant regional role is played by banks in Austria and Denmark (within Europe), Canada and Panama (Americas), Bahrain (Africa and the Middle East), as well as Singapore, Hong Kong SAR and Australia (Asia-Pacific). ${ }^{9}$ The presence of global and regional banking hubs can be visualised in a network graph (Graph 3). Each banking centre is shown in a size proportional to its intermediation score.

\section{Prestige}

An aspect that has not received attention in the analysis so far is the identity of the counterparties that relate to a banking centre. This is taken into

8 This is a consequence of high density in the international banking network. For the 212 banking locations (plus as many non-bank locations), there are $n(n-1)$, nearly 180,000 pairs in the directed network. Of about 168,000 pairs with no reported link from one location to the other, $91 \%$ can be linked through an intermediary, of which there are eight on average.

9 Some of these centres concentrate their portfolios on a set of countries weakly connected to the global hubs. For example, banks in Austria, due to their extensive relations with eastern Europe, advance to rank 1 within Europe. Similarly, banks in Bahrain specialise in attracting petrodollar deposits throughout the Middle East. 


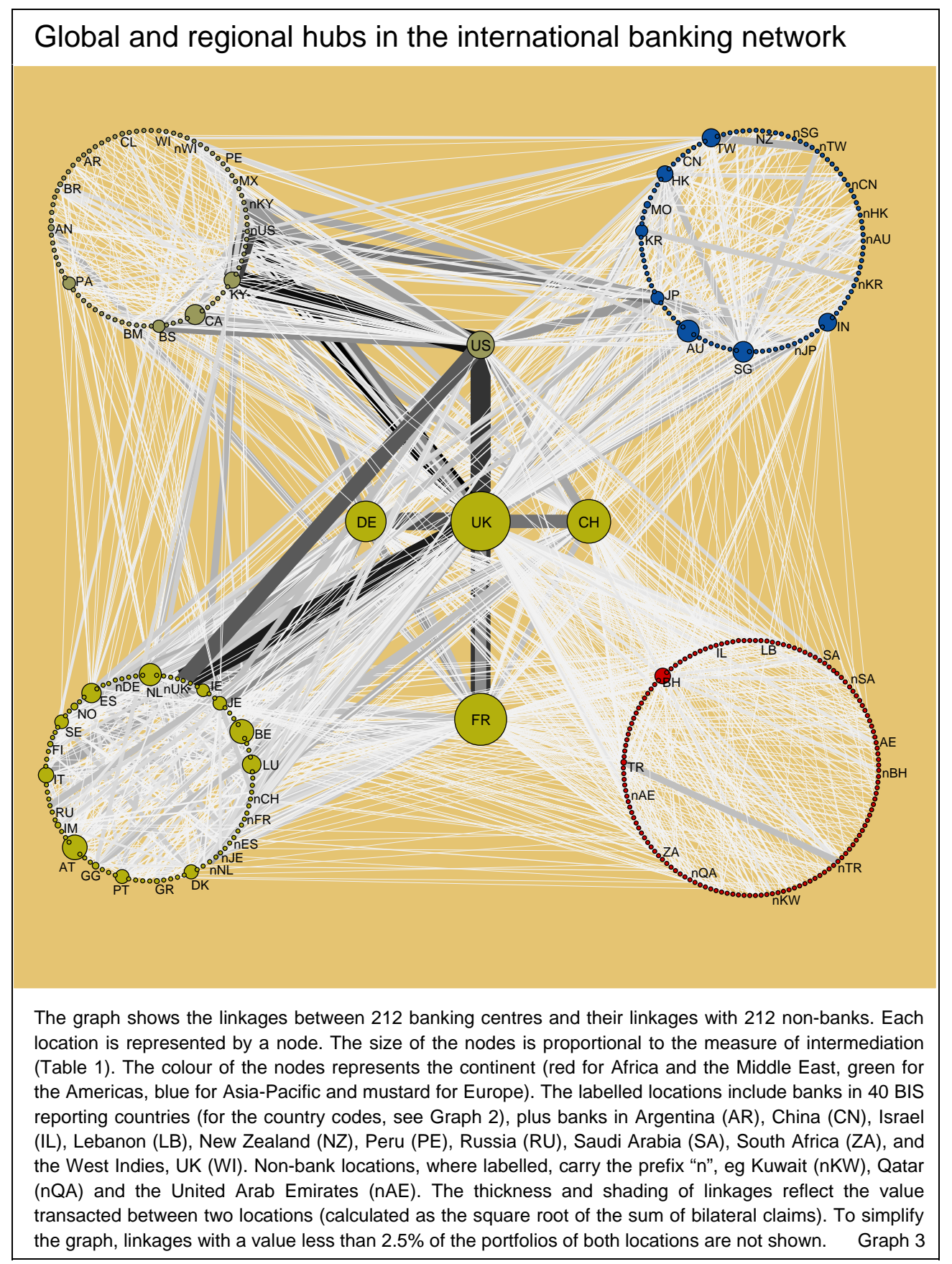

consideration in the following criterion: a banking centre is an important hub if the centres lending to it are themselves important. The idea that the prestige or status of an actor derives from the importance of those nominating him is borrowed from sociology. To compute prestige, each centre receives the same initial score, to which one then adds a term involving the scores of its creditors, weighted by their respective portfolio shares. The prestige scores are then determined simultaneously in a system of equations (see Box).

The results identify as important hubs those centres that also scored highly on other criteria, particularly on market share (Table 2). The United States reclaims the second rank, because having fewer links is offset by the fact that important centres deposit sizeable shares of their portfolios with banks located there. These include the United Kingdom, Jersey, France and the 
Caribbean offshore centres (notably the Cayman Islands and the Bahamas). The Cayman Islands are highly ranked due to their large bilateral link with entities in the United States. The ranks gained by Jersey, Switzerland and Luxembourg can also be attributed to their large liabilities to major international hubs. Hubs bestow importance on each other due to the intensive bilateral links between them. These "highways" on which international banking flows are channelled are highly persistent from quarter to quarter, judging by the constancy in the ranking of links by size. Accordingly, the major linkages in the international banking network visible in Graph 3 also remain stable over time.

\section{Conclusion}

This feature proposes to view the international banking market as a global network in order to identify international banking centres based on the position they occupy in relation to other locations. The range of measures developed from this perspective illustrates that size is only one indicator of a banking centre's multifaceted dimensions. Although the best connected and most central locations are generally also the largest centres, an important network position need not come with size. Where the network measures deviate from market share, they provide complementary information on the role of a centre in the international banking system, eg one of regional intermediation. Just as interestingly, where these measures coincide with size, as for most top-tier banking centres, they may help explain market share: a central position attracts deposits and the participation of foreign banks and thereby contributes to reported size.

The presence of banking hubs is also an important characteristic of domestic banking systems. ${ }^{10}$ That such a characteristic would reproduce itself at the global level is perhaps not surprising, in view of the extensive international activities of the largest banks of various nationalities. Policymakers seem aware of the benefits and issues surrounding financial centres. Yet the formal economics and finance literature offers little guidance on the possible implications for efficiency and stability that such a centralised financial structure with cross-border linkages entails.

10 Recent studies cover Austria (Boss et al (2004)), Italy (lori et al (2007)) and Switzerland (Müller (2003)). Hubs also characterise payment system networks, eg in Japan (Inaoka et al (2004)) and the United States (Soramäki et al (2007)). 


\section{Selected network measures for identifying banking centres}

The network can be expressed in matrix form. The typical element $B_{i j}$ records the value of claims of entities located in country $i$ on entities in country $j$. The network includes banks and non-banks, treated as separate nodes for each of the countries or jurisdictions (212 currently). Hence each index runs from 1 to $n=424$. The matrix can be read in two directions: rows of $B$ represent claims of location $i$ on location $j$, and columns of $B$ represent liabilities of $j$ to each $i$. All diagonal elements $B_{i i}$ are zero, and off-diagonal elements are positive, or zero if there is no associated link. Since linkages between non-reporting banks and between non-banks are not observable, the matrix contains an unobserved block of size $(n-r)^{2}$, where $r$ is the number of reporting countries ( $r=40$ currently). The network is directed, dense and valued, hence $B$ is not symmetric and contains many non-zero entries, each stating claims in millions of US dollars.

The network measures in this feature relate to individual nodes. Each captures an aspect of network centrality of banking centres. To clarify what information they use, the measures are expressed in terms of two variants of $B$. The first, $N$, only records links regardless of their monetary value: $N_{i j}=1$ if $B_{i j}>0$, and 0 otherwise, for all $i, j$. The second, $P$, contains portfolio shares, obtained by scaling each centre's claims on other locations by the size of its overall lending to other locations, $P_{i j}=B_{i j} / \sum_{k} B_{i k}$, for all $i$. Degree, closeness and betweenness use $N$, whereas intermediation and prestige rely on $P$.

Degree is the number of links that emanate from, or point to, a node. The two senses differ in directed networks. There is a direct link from node $i$ to $j$ if $N_{i j}=1$. Node $i$ 's out-degree is the row sum of $N, \sum_{j} N_{i j}$, whereas its in-degree is the column sum, $\sum_{j} N_{j i}$. Dividing by the maximum attainable degree, $(n-1)$, yields degree as reported in Table 1 . The histogram of the number of nodes of given degree is known as the degree distribution.

Closeness and betweenness rely on path counts. If $i$ links to $k$ and $k$ links to $j$, the product $N_{i k} N_{k j}=1$. Hence the sum $\sum_{k} N_{i k} N_{k j}$ gives the number of paths from $i$ to $j$ of length two. More generally, the matrix power $N^{p}$ counts indirect paths of length $\mathrm{p}$. The distance from $i$ to $j$ is the length of the shortest path, $\delta_{i j}=\min _{p}\left[N^{p}\right]_{i j}>0$. It equals one when there is a direct link, two when $i$ reaches $j$ in two steps via another location, and so on. The average distance from $i$ to all other nodes equals $(n-1)^{-1} \sum_{j} \delta_{i j}$, and closeness is its inverse. Betweenness focuses on the nodes that the shortest path passes through. Let $g_{j k}$ denote the number of shortest paths between $j$ and $k$, and $g_{j k}(i)$ the number of those going through node $i$. The probability that $i$ is on a (randomly chosen) shortest path from $j$ to $k$ equals $g_{j k}(i) / g_{j k}$. Betweenness of node $i$ is the sum of these probabilities over all pairs excluding $i, \sum_{j \neq i} \sum_{k \neq i} g_{j k}(i) / g_{j k}$ divided by the maximum this sum can attain, $(n-1)(n-2)$.

The intermediation measure extends betweenness by taking portfolio shares into account. The quantity $\left[P^{2}\right]_{i j}=\sum_{k} p_{i k} p_{k j}$ is the total probability that a dollar sent by $i$ reaches $j$ in two steps. Any location $k$ for which $p_{i k} p_{k j}>0$ is an intermediary to the pair $(i, j)$. The main intermediary is identified as the one transporting the greatest share of the sender's portfolio to the recipient, $h=\arg \max _{k} p_{i k} p_{k j}\left(\right.$ provided $\left.\left[P^{2}\right]_{i j}>0\right)$. This means that a dollar sent by $i$ has a higher likelihood of reaching $j$ through $h$ than through any other banking centre. Conditional on $j$ receiving a dollar from $i$, the likelihood that it is through $k$ equals $p_{i k} p_{k j} /\left[P^{2}\right]_{i j}$. The intermediation measure for a centre $k$ is obtained by summing these probabilities across all pairs $(i, j)$ and normalising by the total number of pairs $n(n-1)$. Instead of a probability, the main intermediary count gives one point, for each pair, to the main intermediary (and zero to all other intermediaries).

Finally, prestige considers in addition the identity of counterparties. The score of a banking centre $i$ consists of the scores of i's creditors weighed by their portfolio shares vis-à-vis $i$, $v_{i}=\sum_{j} P_{j i} v_{j}$. This defines a linear system, $v=P^{\prime} v$, with a non-trivial solution given by the eigenvector associated with the unit eigenvalue. (This is known as Bonacich centrality.) It is preferable to solve the related system $v=\alpha P^{\prime} v+e \Rightarrow v^{*}=\left(I-\alpha P^{\prime}\right)^{-1} e$, where $e$ is the unit vector embodying exogenous importance. (This avoids countries with a zero score contributing nothing to the centrality of others.) The weight on endogenous factors is chosen as $\alpha=1 / 2$, half the unit eigenvalue. Prestige handles valued networks, and takes indirect paths into account through the centrality scores of counterparties. 


\section{References}

Boss, M, H Elsinger, M Summer and S Thurner (2004): "Network topology of the interbank market", Quantitative Finance 4.

Cassis, Y (2006): Capitals of capital: a history of international financial centres, 1780-2005, Cambridge University Press.

Choi, S, A Tschoegl and C Yu (1986): "Banks and the world's major financial centers, 1970-1980", Weltwirtschaftliches Archiv 122(1).

$(1996,2003):$ "Banks and the world's major banking centers", Weltwirtschaftliches Archiv 132(4) and 139(3).

Gehrig, T (2000): "Cities and the geography of financial centers", in Economics of cities: theoretical perspectives, Cambridge University Press.

Hattori, M and Y Suda (2007): "Developments in a Cross-Border Bank Exposure 'Network', proceedings of a CGFS workshop held at the Bank for International Settlements.

Inaoka, H, T Ninomiya, K Taniguchi and T Shimizu (2004): "Fractal network derived from banking transactions - an analysis of network structures formed by financial institutions", Bank of Japan Working Paper no 04-E-04.

Iori G, G de Masi, O Precup, G Gabbi and G Caldarelli (2007): "A network analysis of the Italian overnight money market", Journal of Economic Dynamics and Control, forthcoming.

Johnston, R (1983): The economics of the euro-market: history, theory and policy, Macmillan, New York.

Kindleberger, C (1974): "The formation of financial centers: a study in comparative economic history", Princeton Studies in International Finance, no 36 .

Müller, J (2003): "Two approaches to assess contagion in the interbank market", manuscript.

Newman, M, A Barabási and D Watts (eds) (2006): The structure and dynamics of networks, Princeton University Press.

Niehans, J and J Hewson (1976): "The eurodollar market and monetary theory", Journal of Money, Credit and Banking 8(1).

Reed, H (1981): The preeminence of international financial centers, Praeger Publishers.

Soramäki, K, M Bech, J Arnold, R Glass and W Beyeler (2007): "The topology of interbank payment flows", Physica A 379.

Stigum, M (1990): The money market, 3rd edition, The McGraw-Hill Companies, Inc.

Wasserman, S and K Faust (1994): Social network analysis: methods and applications, Cambridge University Press. 